\title{
Influence of Nanoalumina Particles on the Static and High-Cycle Fatigue Properties of Peel-Loaded Adhesive-Bonded Joints
}

\author{
A. Kubit, ${ }^{a, 1}$ W. Zielecki, ${ }^{a}$ and M. Drabczyk ${ }^{b}$ \\ ${ }^{a}$ Rzeszów University of Technology, Faculty of Mechanical Engineering and Aeronautics, Department \\ of Manufacturing Processes and Production Engineering, Rzeszów, Poland \\ ${ }^{b}$ University of Rzeszów, Faculty of Mathematics and Natural Sciences, Department of Mechanics \\ and Mechanical Engineering, Centre for Innovative Technology, Rzeszów, Poland \\ 1 akubit@prz.edu.pl
}

Results of research are aimed at determining the possibility of improving the static and fatigue properties of peel-loaded adhesive-bonded joints of S235JR steel with an alumina nanopowder dispersed in an epoxy adhesive. The static properties were assessed in a T-peel test. The high-cycle fatigue strength tests were carried out on an electromagnetic inductor with the resonance frequency of the joint specimen. High-cycle fatigue was analyzed at the limited number of cycles $2 \cdot 10^{6}$. The tests were conducted on the specimens bonded with an Epidian 57 epoxy adhesive and a PAC hardener, whose properties were modified through the introduction of an alumina nanopowder. Four versions of the filled epoxy adhesive were examined, 0.5, 1.5, 2, and 3 wt.\% of the dried nanopowder were dispersed in the epoxy adhesive. Fatigue strength tests revealed a significant improvement of the fatigue lifetime of adhesive-bonded joints due to the addition of fillers. In the best case a more than five-fold increase in the fatigue lifetime was obtained (from 199,500 to 1000,000 cycles). The fatigue strength for the best case increased by about 19\%.

Keywords: nanoalumina, fatigue strength, adhesive-bonded joints, peel, T-peel test.

Introduction. Adhesive bonding has become the treatment of choice for joining together different materials. Adhesives play an increasingly important part all over the engineering world and continue finding new applications in different industries [1]. This technology makes use of reactive adhesives based on the polymers containing reactive functional groups [2]. To bond glass, ceramic or metal materials, the structural pressuresensitive adhesives in the form of carrier-free self-adhesive tapes have been successfully used by applying them onto the structural component prior to its heating in a curing oven. They exhibit high heat resistance and adhesion performance [3-5]. Adhesive-bonded joints are now commonly employed, especially in the fields where the reduction in the structure mass is of primary importance. One of the significant advantages of adhesive-bonded joints is the ability to bond different materials, providing uniform stress distribution patterns within the joint and virtually no limitations as regards the thickness of glued components. Therefore, this is an integral technique for the technology of multilayer composites used in the manufacture, e.g., of aircraft structures. Apart from a number of indisputable advantages, there are also serious drawbacks of glued structures, such as relatively low durability and fatigue strength as compared to other joining techniques [6-9]. The best polymer materials for adhesive bonding with high cohesion properties are epoxy resin adhesives [10]. Epoxy resin adhesives are low-molecular-weight substances with so-called epoxy functionality, i.e., a three-membered oxirane-ring containing one oxygen atom linked to two carbon atoms. Among the variety of commercially available epoxy compounds, the most important group of epoxy resins is derived from bisphenol-A. Epoxy resin adhesives are characterized by the cohesion strength, long-term durability, and high resistance to ambient conditions and chemicals. The excellent adhesion properties for metals, mineral surfaces, and wood 
determine a wide scope of their applications in adhesive technology. Structural adhesive joints are often one of the most important parts in load-carrying structures [11]. The advantage of adhesive-bonded joints is their high fatigue strength, but they are highly susceptible to failure caused by interfacial crack initiation and growth [12]. Fatigue strength and lifetime and prediction of these properties for the materials, like epoxy adhesives are important issues in modern engineering design [13].

Epoxy resin adhesives are cured with primary or secondary diamines. A flexibilizing effect is reached by the use of longer-chain diamines, such as polypropylene glycol diamine, amino terminated butadiene-acrylonirile copolymers, and amino amides. Elastic bonds are effected by the use of polythiols of higher molecular weight [14].

In recent years, the conductive filler-loaded polymer composites have been found ever-widening applications due to their versatile properties, including thermal stability, mechanical strength, electrical resistance, and adhesive characteristics [15]. Of those composites, the isotropically conductive adhesives (ICAs), loaded with organic or inorganic fillers, were evaluated as a lead-free alternative for the microelectronic packaging [16]. A number of techniques was discussed that improves the mechanical properties of structural adhesives, containing such fillers, as carbon, nylon or glass micro- or nanofibers $[17,18]$. With time the production of modern composites began to shift from micro- to nanocomposites due to the unique combination of mechanical and physical properties of nanofillers with characteristic sizes below $100 \mathrm{~nm}$, especially nanofillers based on carbon nanotubes $[19,20]$.

Jingchao et al. [9] observed that the addition of silica nanoparticles to a resin significantly effected the tensile properties of modified epoxies. The tensile strength of 3 wt.\% nanosilica reached its maximum. Huang et al. [10] suggested an increase in the tensile strength, breaking elongation, and impact strength of $\mathrm{SiO}_{2}$ /epoxy nanocomposites at an initial silica weight fraction reaching $2 \mathrm{wt} . \%$. Recent studies show that the scientific community is adopting a diversity of different methods to develop nano-reinforced composites with a varying level of success [21]. The properties of carbon nanotube (CNT)-based nanocomposites are influenced by a number of factors that include the CNT synthesis and purification process, geometrical and structural properties, their alignment in the matrix, dispersion and fabrication processes [22-24].

Materials and Method. Static and fatigue strength tests of adhesive-bonded joints were performed on the joints of S235JR steel parts. The epoxy adhesive containing an Epidian 57 epoxy resin with a PAC hardener, supplied by CIECH Sarzyna S.A (Poland), was investigated. An alumina nanopowder with a 40-nm average particle size supplied by Sigma Aldrich was used as a nanofiller, it was dispersed in the epoxy matrix in the unmodified state. The adherend surfaces were treated with different methods. The reason was that often used sand blasting causes the distortion of plates used to prepare specimens for the T-peel test. Hence, the adherend surfaces for this test were grinded with abrasive flap wheels. For fatigue tests sand blasting of surfaces was used.

Each surface to be glued was subjected to sand blasting with $95 \mathrm{~A}$ aloxite under the following conditions: grain size $w_{z}=0.27 \mathrm{~mm}$, air pressure $p=0.8 \pm 0.1 \mathrm{MPa}$, and blasting time $t=60 \mathrm{~s}$.

The same methods of preparing and the hardening conditions of adhesive compositions were employed for all joint versions in static and fatigue tests.

The adhesive compositions with nanofillers were prepared in the following subsequent stages:

(i) nanopowders were dried at $80^{\circ} \mathrm{C}$ for $1 \mathrm{~h}$;

(ii) epoxy resin was heated up to $40^{\circ} \mathrm{C}$ to reduce its viscosity;

(iii) required nanofiller amount was added to the resin;

(iv) high-speed mechanical mixing and ultrasonication of the resin with the nanofiller at the constant temperature of $40^{\circ} \mathrm{C}$; 
(v) after self-cooling a required hardener amount was added and mixed mechanically for $2 \mathrm{~min}$.

The hardening process of adhesive-bonded joints lasted for $24 \mathrm{~h}$ at room temperature $\left(20 \pm 3^{\circ} \mathrm{C}\right)$ under the constant pressure of $0.1 \mathrm{MPa}$ applied to the joint. Adhesive flashes on the specimen surface were removed immediately before the tests. As a result, the thickness of an adhesive layer was about $0.1 \mathrm{~mm}$.

The basic versions of the specimens were bonded with an Epidian 57 epoxy adhesive and a PAC hardener, in the proportion: 100 parts by weight of the epoxy resin per 80 parts by weight of the hardener. To the modified versions a nanofiller was added in the amounts given in Table 1.

$\mathrm{T}$ a b 1 e 1

Nano $\mathrm{Al}_{2} \mathrm{O}_{3}$-Epoxy Adhesive Versions

\begin{tabular}{|c|c|c|}
\hline Number & Code & Nano $\mathrm{Al}_{2} \mathrm{O}_{3}$ content (wt.\%) \\
\hline 1 & $\mathrm{E} 0$ & 0 \\
\hline 2 & $\mathrm{E} 0.5$ & 0.5 \\
\hline 3 & $\mathrm{E} 1.5$ & 1.5 \\
\hline 4 & $\mathrm{E} 2$ & 2.0 \\
\hline 5 & $\mathrm{E} 3$ & 3.0 \\
\hline
\end{tabular}

A set of T-peel tests was conducted on the specimens shown in Fig. 1. The width of the joints was $25 \mathrm{~mm}$, the length of the tab portion was $75 \mathrm{~mm}$, and the bond length was $100 \mathrm{~mm}$. As adherends, 1-mm thick cold-rolled S235JR steel was used. After curing the bent tabs, the specimens were tested on a Zwick Z100 testing machine. The specimens were tested at a crosshead displacement rate of $10 \mathrm{~mm} / \mathrm{min}$ at room temperature. The two loads were recorded for each test: static strength (peak load/force to initiate failure) and average peeling force. The peel forces vs crosshead displacement curves were recorded during peeling. Four replicate specimens were used for each joint configuration.

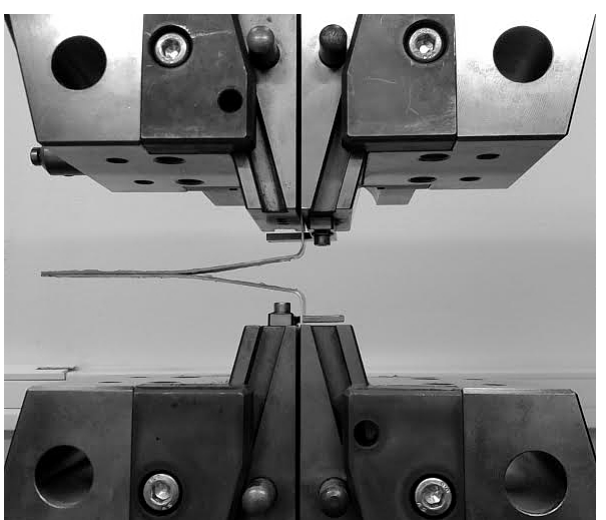

a

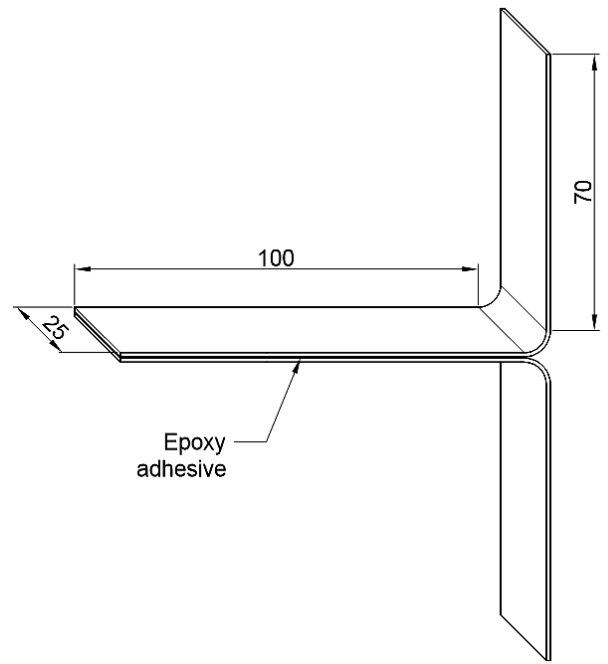

$\mathrm{b}$

Fig. 1. T-peel specimen for the static test (a) and specimen dimensions (b). 
Fatigue strength tests were conducted with an ETS Solutions L Series MPA-102L620M electromagnetic vibration inductor. The system offers the possibility of applying loads with harmonic, stochastic, and fast-varying/shock waveforms and has the function of searching, tracing, and maintaining the resonance frequency. The device generates fastvarying signals with sinusoidal, saw-toothed, trapezoid, and rectangular waveforms. The maximum frequency of the generated signals is $4500 \mathrm{~Hz}$. The measuring setup was additionally equipped with external sensors, such as a laser displacement sensor for the measurement of the specimen vibration amplitude and an accelerometer. The entire measuring setup was linked to PC. The software, developed specifically to support the measurement procedure, made it possible to control the measurement process, which consisted in maintaining the specimen vibration at its resonance frequency. The resonance frequency of the specimen was identified automatically by the measuring system within the frequency range defined by the user. The specimen for the fatigue tests and photograph of the functional setup are shown in Fig. 2.

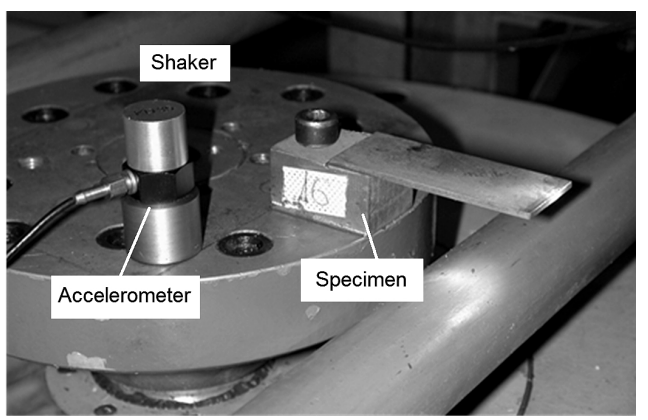

a

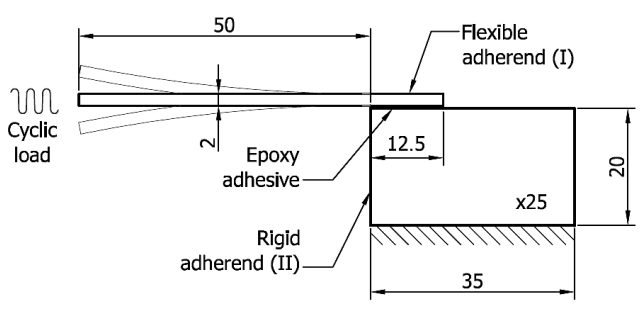

b

Fig. 2. Joint specimen mounted on the shaker (a) and specimen dimensions (b) used in peel fatigue strength testing.

The specimens for each version were subjected to resonance vibrations at four different amplitude levels, where the number of cycles was counted up to the point when it was no longer possible to maintain the vibrations of the specimen at a given amplitude level, which was the evidence of fracture. For each level, the tests were repeated four times. The lowest dynamic load is the value whereby the specimen does not fail after loading with $2 \cdot 10^{6}$ cycles.

The fatigue test system was equipped with an accelerometer and laser system to measure the vibration amplitude for adherend I. Based on the amplitude value and FEM analysis, the maximum stress in the adhesive joint was determined.

The results of fatigue strength tests were processed. The results for specimens bonded with a neat Epidian 57 adhesive and PAC hardener are summarized in Table 2.

Results and Discussion. Static strength testing results obtained in the T-peel test are summaized in Table 3. The static strength tests revealed a significant effect of the nanofiller on the failure mode. Especially for the filler contents of 1.5 and $2 \mathrm{wt} . \%$, the peak load is significantly higher as compared to the neat version (E0). Whereas at the later stage of fracture this trend reverses, which determines the value of average peeling force, being higher for all versions of neat epoxy. The version with $3 \mathrm{wt} . \%$ of nanoalumina exhibited a decrease in peak load and average peeling force values.

In the fatigue process, the failure of a joint has to do with the value of resonance frequency. A loss of load capacity by the bonded joint is associated with a sudden drop in resonance. 
$\mathrm{T}$ a b 1 e 2

\section{Results of Fatigue Tests for an E0 Version}

\begin{tabular}{|c|c|c|c|}
\hline \multirow[t]{2}{*}{ Stress amplitude (MPa) } & \multicolumn{3}{|c|}{ Values for individual specimens } \\
\hline & 25.5 & 24.1 & 21.0 \\
\hline \multirow[t]{4}{*}{ Number of cycles to fracture $N \cdot 10^{3}$} & 100 & 280 & 900 \\
\hline & 150 & 350 & 1150 \\
\hline & 180 & 400 & 1350 \\
\hline & 180 & 420 & 1500 \\
\hline Average value $\bar{N}$ & 152.5 & 362.5 & 1225.0 \\
\hline Average value $\overline{\log N}$ & 5.1717 & 5.5541 & 6.0803 \\
\hline Standard deviation $S D$ & 0.1204 & 0.0788 & 0.0965 \\
\hline Coefficient of variation $W_{S D}=\frac{S D}{\overline{\log N}} \cdot 100 \%$ & 2.33 & 1.42 & 1.59 \\
\hline Value $t_{\alpha}$ for the confidence level $P=95 \%(\alpha=0.05)$ & 3.182 & 3.182 & 3.182 \\
\hline$t_{\alpha} \cdot S D$ & 0.3830 & 0.2507 & 0.3072 \\
\hline Fatigue strength $Z_{G}, \mathrm{MPa}$ & & 19.5 & \\
\hline Fatigue lifetime $N_{0} \cdot 10^{3}$ cycles (for $\sigma=24.1 \mathrm{MPa}$ ) & & 362.5 & \\
\hline Equation of linear regression for the fatigue curve & $\sigma=$ & $365 \log N$ & .52 \\
\hline
\end{tabular}

$\mathrm{T}$ a b 1 e 3

Results of T-Peel Tests

\begin{tabular}{|c|c|c|}
\hline Version & Peak load $(\mathrm{N}) / S D$ & Average peeling force $(\mathrm{N}) / S D$ \\
\hline E0 & $142.66 / 8.31$ & $70.04 / 8.00$ \\
\hline E0.5 & $149.14 / 13.05$ & $62.07 / 9.70$ \\
\hline E1.5 & $158.91 / 12.48$ & $49.34 / 9.19$ \\
\hline E2 & $164.77 / 10.34$ & $50.26 / 7.25$ \\
\hline E3 & $131.42 / 14.98$ & $57.04 / 9.48$ \\
\hline
\end{tabular}

Fatigue tests revealed a cohesive failure mode for an adhesive joint in most cases. Figure 3a exemplifies the scheme of typical changes in resonance frequency during the fatigue test that demonstrates its permanent decrease. This phenomenon is determined by gradual fracture of adhesive bonds. The process proceeds in the two stages, at the first step the resonance frequency falls very slowly, and when the joint is fractured to a great extent, the frequency decreases rapidly until complete failure. The fatigue process in the joint is shown in Fig. $3 b$.

The results of fatigue strength tests show the possibility of improving the fatigue properties of adhesive joints by addition of an alumina nanopowder as a filler for epoxy adhesives at each of examined contents. The fatigue curves for the basic versions and those with nanofillers are compared in Fig. 4. 


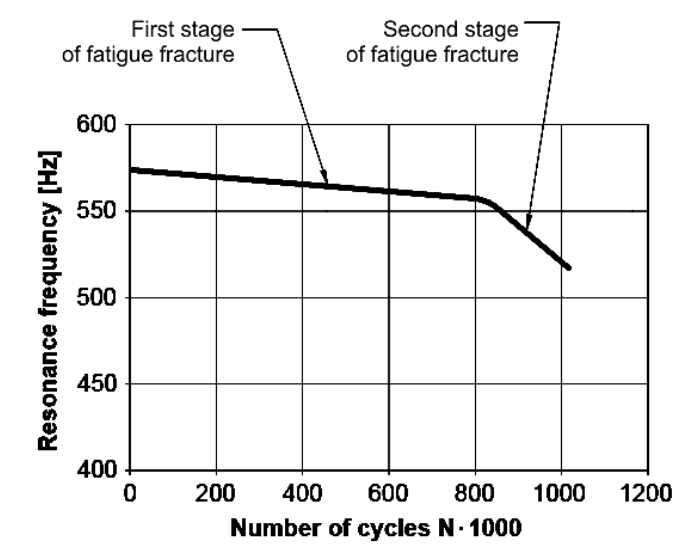

a

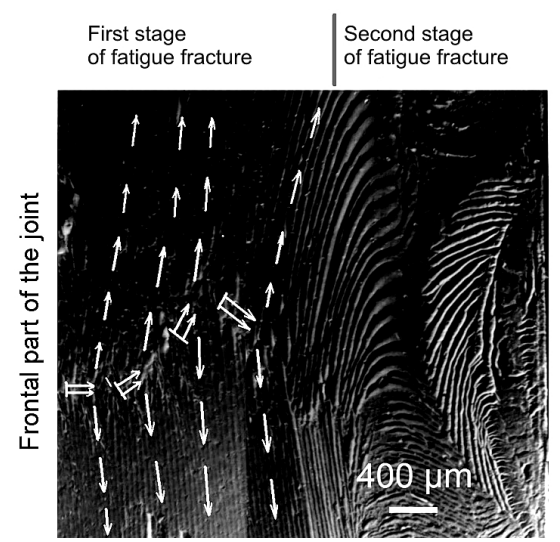

$\mathrm{b}$

Fig. 3. Resonance frequency vs number of cycles (a) and microphotograph of the fatigue fracture surface (b).

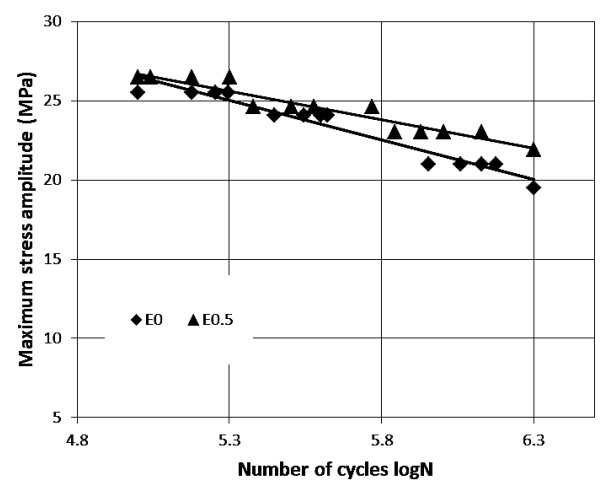

a

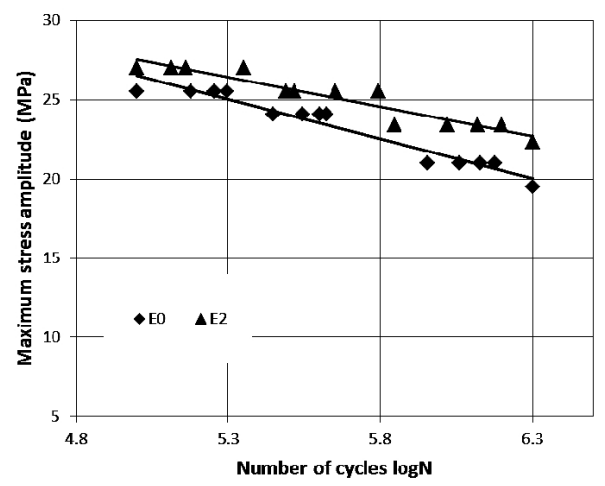

c

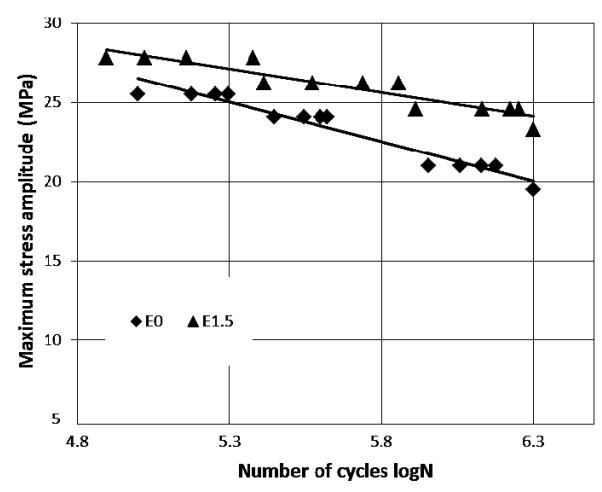

b

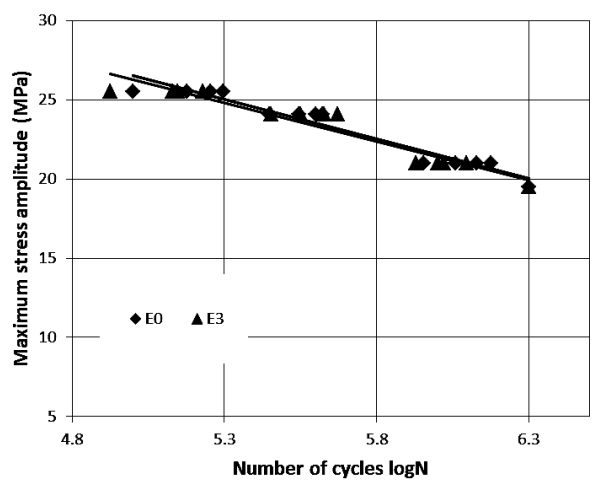

d

Fig. 4. Comparison of the stress-life curve for the neat version (E0) of an epoxy adhesive with those of the adhesive joints filled with an alumina nanopowder: (a) 0.5, (b) 1.5, (c) 2.0, and (d) 3.0 wt.\%.

The results of fatigue tests demonstrate a significant improvement of the fatigue lifetime, e.g., in the case of an E1.5 version at the stress amplitude of $25 \mathrm{MPa}$, an increase in the fatigue lifetime was obtained, from 199,500 to 1000,000 cycles (increase by 401\%). 
In the best results for the adhesive composition filled with $1.5 \mathrm{wt} . \%$ of nanoalumina, the fatigue strength increased from 19.5 to $23.27 \mathrm{MPa}$ (increase by $19.3 \%$ ) as compared to an E0 version (Fig. 4b). For E0.5 and E2 versions, inferior results were obtained, however, an increase in their fatigue strength was revealed (Fig. 4a, c), while a decrease in the lifetime and fatigue strength was found for a $3 \mathrm{wt} \%$ nanoalumina content (Fig. 4d).

The effect of different nanofiller contents on the fatigue strength and lifetime was demonstrated by the bar charts (Fig. 5). Fatigue lifetime values for all versions were given for the stress amplitude of $25 \mathrm{MPa}$.

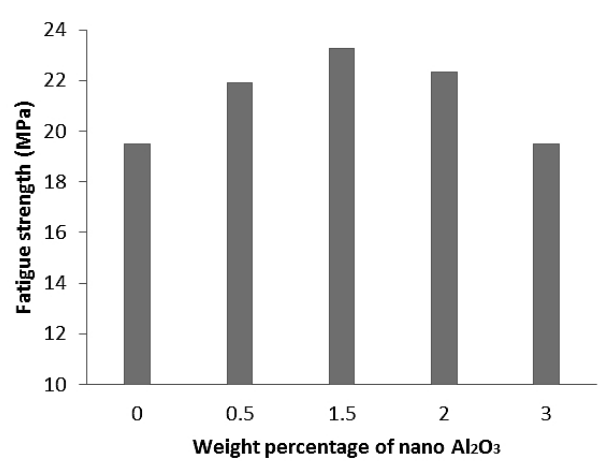

a

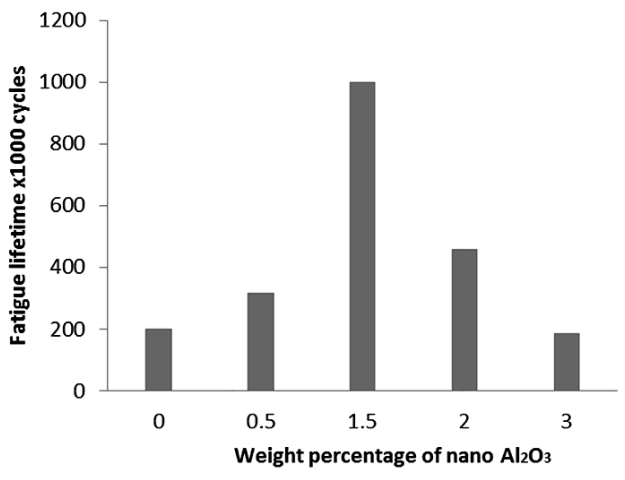

b

Fig. 5. Fatigue strength (a) and fatigue lifetime (b) vs nanoalumina content.

It is commonly known that the properties of epoxy-based nanocomposites strongly depend on a proper dispersion of nanoparticles and the content of agglomerates and aggregates. Figure 6 shows SEM images of a cured epoxy adhesive filled with a nanoalumina powder of the version that revealed the best results, i.e., E1.5 (Fig. 6a) and the version that exhibited a decrease in static and fatigue properties, i.e., E3 (Fig. 6b). In the first case, the aggregates and uniformly dispersed nanoparticles are visible whereas in the second case, the agglomerates dominate.

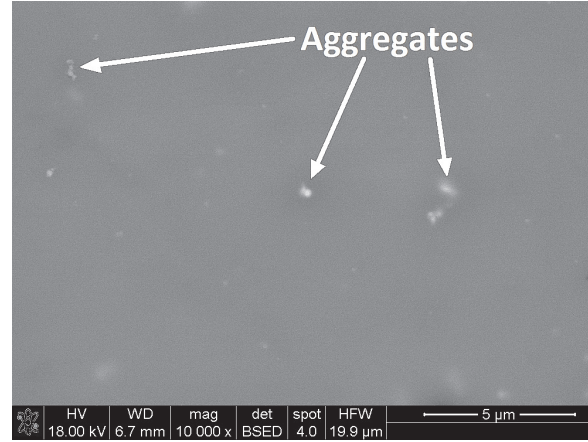

a

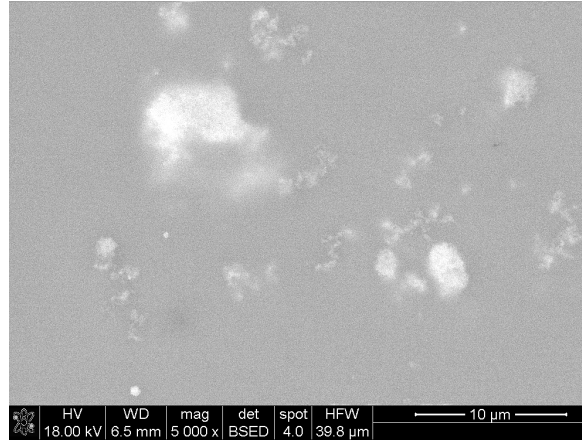

b

Fig. 6. SEM images of an epoxy resin with an alumina nanopowder for 1.5 (a) and 3 wt.\% (b) contents.

In the case of the dominance of agglomerates that have sizes of a few micrometers and larger, nanocomposites cease to be. Thus, it can be concluded that this method of preparing the composition is not effective at higher filler contents.

The possibility of improving the strength properties at variable cyclic loads with nanofillers was confirmed for the case of an alumina nanopowder. The previous research 
of the impact of multiwall carbon nanotubes on the fatigue strength of adhesive joints [25] shows that the impact of both nanofillers on the properties of adhesive-bonded joints is similar.

The authors [26] explain that the mechanism of improving some mechanical properties with nanofillers in the epoxy matrix is related to their addition that provides an additional source of energy absorption. Nanofillers absorb more energy, which is dissipated in the vicinity of nanoparticles, thus taking more time to penetrate into the basic specimen material [17, 26-28].

Conclusions. The study offers an experimental insight into the fatigue strength properties of four epoxy adhesive polymers containing nanoalumina. The results of the experiment clearly suggest that the addition of the filler to epoxy adhesives improves their properties, such as static and fatigue strengths and their fatigue lifetime when the peel stress is dominant.

The results of the research show that nanotechnology can contribute to the improvement and, therefore, to the more widespread use of adhesive-bonded structures.

The strength properties of adhesive-bonded joints depend on many factors, including the class of the adhesive composition, the method used to treat the surfaces to be joined, the adhesive hardening conditions of a joint, and the structure of the adhesive-bonded joint. The strength of adhesive-bonded joints can be enhanced by modifying the adhesive compositions. Such modification consists in introducing the required chemical compounds or fillers to the adhesive. The powders or granulates of copper, aluminium, aloxite, aluminium silicate, and chalk as well as glass, graphite, quartz, and metal fibers are most commonly used as epoxy resin fillers. Modifying the adhesive compositions with nanofillers can increase the durability and strength of adhesive-bonded joints by $25-30 \%$.

Recent progress in the production of nanoparticles (nanopowders, nanotubes) permits of obtaining solid particles smaller than $100 \mathrm{~nm}$ that are characterized by a well-developed specific surface. The "unsaturated" nature of atomic bonds of the nanoparticle surface results in the absorption of substances purposely introduced to the environment, which contributes to the improvement of mechanical properties of composites, which contain nanomaterials, and of other properties, such as electric conductivity (possibility to obtain current-conducting plastic composites). Such properties of nanomaterials were an incentive to also use them in adhesive compositions.

1. B. Bartczak, J. Mucha, and T. Trzepieciński, "Stress distribution in adhesively-bonded joints and the loading capacity of hybrid joints of car body steels for the automotive industry," Int. J. Adhes. Adhes., 45, 42-52 (2013).

2. W. Brockmann, P. L. Gei $\beta$, J. Klingen, B. Schröder, Adhesive Bonding, WILEY-VCH Verlag, Weinheim (2009).

3. D. Sowa, Z. Czech, and Ł. Byczyński, "Peel adhesion of acrylic pressure-sensitive adhesives on selected substrates versus their surface energies," Int. J. Adhes. Adhes., 49, 38-43 (2014).

4. H. Lee and K. Neville, Epoxy Resins: Their Applications and Technology, Literary Licensing, LLC (2012).

5. K. Kowalczyk, A. Kowalczyk, and Z. Czech, Synthesis and properties of solid structural adhesives modified in-situ using $1 \mathrm{D}$ and 2D-type microfillers, Int. J. Adhes. Adhes., 32, 76-81 (2012).

6. Z. Czech, A. Kowalczyk, R. Pelech, et al., "Using of carbon nanotubes and nano carbon black for electrical conductivity adjustment," Int. J. Adhes. Adhes., 36, 20-24 (2012). 
7. F. Rosselli, "Making the move from conventional joining to structural adhesives," Reinf. Plast., 50, No. 2, $42-46$ (2006).

8. USA Patent 2004/0242835, Resolution Performance Products (2004).

9. D. Caile, J. P. Pascault, and L. Tighzert, "Reaction of a diepoxide with a diisocyanate in bulk," Polym. Bull., 24, 23-30 (1990).

10. R. Pilawka, J. Kowalska, and Z. Czech, "Effect of 1-substituted imidazole derivatives for the curing process of epoxyisocyanate composition," Polish J. Chem. Technol., 15, No. 4, 1-6 (2013).

11. L. Tong, J. K. Spelt, and G. Fernlund, "Strength determination of adhesive bonded joints," in: L. Tong and C. Soutis (Eds.), Recent Advances in Structural Joints and Repairs for Composite Materials, Kluwer Academic Publishers, Dordrecht (2003), pp. 27-66.

12. V. Alfred Franklin and T. Christopher, "Interlaminar fracture toughness estimation of aerospace composites by weighted residual approach," Strength Mater., 47, No. 6, 789-796 (2015).

13. Wenli Zhao, Xiaojun Zhou, and Meina Shen, "A method of virtual design of the fatigue life of a dynamic structure," Strength Mater., 47, No. 3, 507-513 (2015).

14. R. Pilawka and K. Goracy, "Investigation of curing process for epoxy-isocyanate compositions," Kompozyty, 11, 44-48 (2011).

15. B.-S. Yim and J.-M. Kim, "Characteristics of isotropically conductive adhesive (ICA) filled with carbon nanotubes (CNTs) and low-melting-point alloy fillers," Mater. Trans., 51, No. 12, 2329-2331 (2010).

16. F. H. Gojny, M. H. G. Wichmann, B. Fiedler, et al., "Influence of nano-modification on the mechanical and electrical properties of conventional fibre-reinforced composites," Composites: Part A, 36, 1525-1535 (2005).

17. F. H. Gojny, M. H. G. Wichmann, B. Fiedler, and K. Schulte, Influence of different carbon nanotubes on the mechanical properties of epoxy matrix composites - a comparative study, Compos. Sci. Technol., 65, 2300-2313 (2005).

18. J. M. Wernik and S. A. Meguid, "Multiscale micromechanical modelling of the constitutive response of carbon nanotube-reinforced structural adhesives," Int. J. Solids Struct., 51, 2575-2589 (2014).

19. J. M. Wernik and S. A. Meguid, "On the mechanical characterization of carbon nanotube reinforced epoxy adhesives," Mater. Des., 59, 19-32 (2014).

20. G. Gkikas, D. Sioulas, A. Lekatou, et al., "Enhanced bonded aircraft repair using nano-modified adhesives," Mater. Des., 41, 394-402 (2012).

21. Y. Rostamiyan, "Modeling and analysis of the tensile and flexural properties of a fiber-orientated hybrid nanocomposite using Taguchi methodology, Strength Mater., 47, 820-834 (2015).

22. H. Liu, X. Wang, P. Fang, et al., "Functionalization of multiwalled carbon nanotubes grafted with self-generated functional groups and their polyamide 6 composites," Carbon, 48, 721-729 (2010).

23. N. G. Sahoo, H. K. F. Cheng, J. Cai, et al., "Improvement of mechanical and thermal properties of carbon nanotube composites through nanotube functionalization and processing methods," Mater. Chem. Phys., 117, 313-320 (2009).

24. F. H. Gojny, M. H. G. Wichmann., U. Kopke, et al., "Carbon nanotube reinforced epoxy composites; enhanced stiffness and fracture toughness at low nanotube content," Compos. Sci. Technol., 64, 2363-2371 (2004). 
25. A. Kubit, M. Bucior, and W. Zielecki, "The impact of the multiwall carbon nanotubes on the fatigue properties of adhesive joints of 2024-T3 aluminium alloy subjected to peel," Proc. Struct. Integr., 2, 334-341 (2016).

26. A. H. Barber, S. R. Cohen, and H. D. Wagner, "Measurement of carbon nanotubepolymer interfacial strength," Appl. Phys. Lett., 23, 4140-4143 (2003).

27. S. Singh, V. K. Srivastava, and R. Prakash, "Influences of carbon nanofillers on mechanical performance of epoxy resin polymer," Appl. Nanosci., 5, 305-313 (2015).

28. S. Singh, V. K. Srivastava, and R. Prakash, "Characterization of multiwalled carbon nanotube reinforced epoxy resin composites," Mater. Sci. Technol., 29, 1130-1134 (2013). 